\title{
MIGRAÇÃO, IDENTIDADE E RETERRITORIALIZAÇÃO EM PRECISAMOS DE NOVOS NOMES, DE NOVIOLET BULAWAYO, E "NO SEU PESCOÇO", DE CHIMAMANDA NGOZI ADICHIE
}

\author{
Shirley Carreira (UERJ/FFP) \\ Victória Cristina Bezerra (UERJ)
}

Resumo: Este trabalho propõe a análise de textos literários que promovem não só a representação de diferentes formas de relação dos imigrantes com a terra natal, mas também o processo de reconfiguração das identidades no país de acolhimento. Para tanto, serão examinados o romance Precisamos de novos nomes, de NoViolet Bulawayo, e o conto "No seu pescoço", de Chimamanda Ngozi Adichie.

Palavras-chave: Migração; Identidade; Reterritorialização.

Abstract: This paper proposes the analysis of literary texts that promote not only the representation of different forms of relation of the immigrants with their homelands, but also the process of reconfiguration of their identities in the host countries. To do so, we will examine the novel We Need New Names, by NoViolet Bulawayo, and the short-story "The Thing Around Your Neck," by Chimamanda Ngozi Adichie.

Keywords: Migration; Identity; Reterritorialization.

\section{INTRODUÇÃO}

V vínculo com a terra natal deriva de uma circunstância básica: o espaço concebido como lugar antropológico ${ }^{1}$, que, segundo Marc Augé (1994), é identitário, relacional e histórico. Há um conjunto de elementos definidores

1 O lugar antropológico é a construção concreta e simbólica do espaço que designa um lugar que é identitário, relacional e histórico e, portanto, responsável pelo sentido do pertencimento. 
da identidade singular que vinculam o indivíduo ao seu lugar natal, como o local de nascimento e as regras de residência. A par disso, esse é também o local onde ele estabelece relações sociais e compartilha memórias e traços culturais.

Se por um lado, como Augé (1994) enfatiza, os processos de simbolização colocados em prática pelos grupos sociais concorrem para uma sensação de estabilidade identitária, por outro, o deslocamento é o oposto, pois implica uma desterritorialização² que pode ser provisória, no caso dos viajantes, ou permanente, no caso dos migrantes e nômades.

Em geral, o abandono do território acaba por gerar a necessidade de reterritorialização, ou seja, de reconstruir o lugar em outro espaço. Essa é a tendência do migrante, que busca refazer o território na pátria de adoção. A relocalização "engendra novos espaços, que enfraquecem os laços precedentes" (CANCLINI, 2008, p.202) à medida que novas experiências surgem e novos laços vão sendo estabelecidos.

Este trabalho visa à análise de dois textos literários que promovem não só a representação de diferentes formas de relação dos imigrantes com a terra natal, mas também o processo de reconfiguração das identidades

2 Os conceitos de "desterritorialização" e "reterritorialização" foram desenvolvidos por Gilles Deleuze e Felix Guattari e utilizados pela primeira vez em $O$ anti-Édipo (1972) e, posteriormente, em Kafka: por uma literatura menor (1975), Rizoma (1976), Mil platôs - capitalismo e esquizofrenia (1980) e O que é filosofia?(1991). 
no país de acolhimento: o romance Precisamos de novos nomes, de NoViolet Bulawayo, e o conto "No seu pescoço", de Chimamanda Ngozi Adichie.

Os estudos sobre as relações entre mobilidades culturais e literatura fizeram emergir uma nova categoria de autor: o escritor migrante, que, segundo Salman Rushdie (1991, p.16), é um indivíduo "traduzido", a quem cabe "enfrentar cotidianamente os problemas de definição, a dupla perspectiva de quem se vê, a um só tempo, dentro e fora da sociedade em que vive" (CARREIRA, 2009, p.3). $\mathrm{Na}$ perspectiva de Rushdie, o termo "tradução" não se reporta "prioritariamente aos processos interlinguísticos de transferência de significados, mas ao deslocamento e à inserção de sujeitos num novo meio cultural que, por sua vez, se hibridiza com a sua presença" (BLUME, 2014, p.60).

As obras selecionadas foram escritas por autoras africanas migrantes, radicadas nos Estados Unidos. Chimamanda Ngozie Adichie é nigeriana, mas construiu a sua carreira literária em outro país, os Estados Unidos da América, para onde emigrou aos dezenove anos. Escritora versátil, Adichie transita pelo conto, poesia, ensaio e romance, sendo este último o gênero em que obteve reconhecimento da crítica e de público. A sua militância em prol da mulher é igualmente 
responsável pelo seu sucesso internacional. O conto "No seu pescoço", publicado no Brasil pela Companhia das Letras em uma coletânea com o mesmo título, foi, na realidade, publicado nos EUA em 2002, com o título "You in America", depois de ser indicado para o Caine Prize for African Writing.

NoViolet Bulawayo nasceu no Zimbábue e migrou para os Estados Unidos aos dezoito anos para concluir seus estudos. Sua primeira incursão na literatura foi por meio de contos que foram publicados em algumas coletâneas. Em 2012, ela recebeu o prêmio Caine Prize for African Writing, pelo conto "Hitting Budapest", que originou Precisamos de novos nomes, seu romance de estreia. Premiado romance, diga-se de passagem, uma vez que Bulawayo recebeu o Guardian First Book Award, o Hemingway/PEN Award para romance de estreia, e ainda foi finalista do Man Booker Prize em 2013.

$\mathrm{Na}$ condição de mulheres, imigrantes e negras, elas narram a complexidade do processo de reterritorialização, que implica a superação da tripla ruptura que o migrante sofre com o espaço, o idioma e a cultura natal (RUSDHIE, 1991). Muito embora, as personagens dos romances sejam oriundas de ex-colônias inglesas, em que o idioma inglês permanece como segunda língua, as protagonistas apresentam certa dificuldade de comunicação devido a aspectos culturais. 
"As raízes, o idioma e as normas sociais são, assim, três importantes elementos constituintes da identidade cultural. Ao negá-los, o imigrante é compelido a encontrar novos meios de descrever-se e definir-se como indivíduo" (CARREIRA, 2012, p.82). Pode-se então afirmar que o grande dilema do migrante é a tensão dialética entre a tradição e a tradução, pois há que "habitar, no mínimo, duas identidades, falar duas linguagens culturais" e traduzir e negociar entre elas (HALL, 1998, p.89).

\section{ENTRE PARTIDAS E CHEGADAS: O CHOQUE CULTURAL}

Os Estudos Culturais trouxeram à baila discussões acerca do conceito de identidade, demonstrando que o homem passou por diferentes formas de percepção identitária, desde o sujeito do lluminismo, visto como detentor de uma identidade unificada e imutável; passando por uma perspectiva sociológica, fruto da interação entre o eu e a sociedade, até atingir a concepção pós-moderna de identidade, em constante mutação, "transformada continuamente em relação às formas pelas quais somos representados ou interpelados pelos sistemas culturais que nos rodeiam" (HALL, 1987, p.13). Por outro lado, o esbatimento de fronteiras levou a uma nova compreensão do sentido de pertencimento, não mais vinculado ao espaço geográfico 
ou ao conceito tradicional de nação, mas concebido em relação a uma "comunidade imaginada" (ANDERSON, 2008).

Se, por um lado, os movimentos diaspóricos ensejam amalgamentos, identidades híbridas ${ }^{3}$, resultantes do encontro entre culturas, por outro, o processo de integração a uma nova cultura se dá com diferentes gradações da manutenção dos vínculos com as raízes culturais, e, consequentemente, com o território. As protagonistas das obras que constituem o corpus literário deste trabalho se enunciam a partir de um espaço intersticial, na zona de contato intercultural, mas nunca de uma forma estereotipada, e sim como indivíduos, que, em circunstâncias particulares, posicionamse diferentemente quanto à questão da imigração.

A protagonista de Precisamos de novos nomes é Darling, uma menina que vive em uma comunidade pobre de um país africano não nomeado, mas facilmente identificável como o Zimbábue. No romance, a miséria, assim como a violência, está sempre presente e, de certo modo, quase naturalizada, dada a sua constância. A história narrada nos permite situar temporalmente a ação no governo de Robert Mugabe, líder do país após a independência, que esteve no poder por trinta anos e foi responsável por um sangrento conflito interno.

3 O hibridismo cultural reporta-se a identidades formadas em lugares intersticiais, ou entrelugares, e não mais a identidades puras (BHABHA, 1998). 
A comunidade, paupérrima e ironicamente denominada Paraíso, ergueu-se em um local periférico em que muitas famílias passaram a viver depois de terem suas casas demolidas durante os conflitos políticos internos. Durante o período em que viveu no Paraíso, Darling e seus amigos desenvolveram o hábito de ir a um local próximo, denominado Budapeste, para roubar goiabas e matar a fome que os consumia. Nessas incursões e mesmo durante as brincadeiras com os amigos, Darling sempre expressa a esperança de que, um dia, sua tia Fostalina venha buscá-la para viver com ela em Detroit, nos Estados Unidos. Esse seu desejo é frequentemente alvo da zombaria das outras crianças. Ainda assim, Darling persiste no sonho e elabora uma versão idealizada do país que ela chama carinhosamente de "minha América".

O romance é dividido em duas partes. A primeira narra a vida da protagonista na comunidade do Paraíso e a segunda relata a sua trajetória nos Estados Unidos. Entremeados à narrativa, há ainda três capítulos escritos como monólogos, que de um modo quase elegíaco, se reportam a três momentos importantes no romance: a chegada ao Paraíso, a partida para a América e a condição do imigrante. A voz que se faz ouvir nesses capítulos não pertence à Darling. Soa como uma voz coletiva, como uma memória grupal compartilhada. 
Dada a especificidade deste trabalho, abordaremos especificamente os capítulos que se reportam à vida da protagonista na América, recorrendo, quando necessário, a essa memória coletiva que emerge como voz intrusa no romance.

Ainda criança, Darling experimentara a sensação de deslocamento e exclusão em sua própria pátria, quando sua família foi destituída de suas posses e foram obrigados a deixar a casa em que viviam. Essa experiência não é diretamente relatada por Darling, mas o leitor toma conhecimento dela por meio do narrador intruso, que expressa a memória da coletividade, capítulo intitulado "Como eles apareceram":

Eles não vieram para o Paraíso. Vir significaria que escolheram. Que primeiro olharam para o sol, sentaram-se de pernas cruzadas [...] e ponderaram a decisão. [...] eles não vieram, não. Eles só apareceram [...] apareceram em fila indiana, feito formigas. Em enxames, feito moscas. Em ondas zangadas, como um mar triste. Apareceram com a poeira de suas casas esmagadas agarrada aos cabelos, à pele e às roupas [...] apareceram carregando varas com as quais marcaram o terreno onde um barraco ia começar e terminar. (BULAWAYO, 2014, p.69)

As dificuldades enfrentadas pelos moradores da comunidade são responsáveis pelo desejo - acalentado por muitos - de emigrar, o que, efetivamente, não acontece apenas com Darling, mas também com vários de seus amigos de infância. 
Os primeiros dias da protagonista em solo americano geram um conflito interior entre a saudade da terra natal, dos familiares e amigos e a necessidade de ficar. O clima, a falta de identificação com a família da tia e a estranheza ante os hábitos dos norte-americanos tornam aguda a sensação do choque cultural:

Se estivesse em casa eu sei que não ficaria sem sair por que uma coisa chamada neve estava me impedindo de ir lá fora viver a vida. Talvez eu e a Sbho e o Bastard e a Chipo e Godknows e o Stina estaríamos em Budapeste, roubando goiabas. Ou estaríamos brincando de encontrar Bin Laden ou do jogo dos países ou de queimada. Mas por outro lado não teríamos comida suficiente, e é por isso que vou tolerar ficar na América aguentando a neve; tem comida para comer aqui [...] mas tem horas que não importa quanta comida eu coma, vejo que a comida não faz nada por mim, como se estivesse com fome pelo meu país e nada fosse resolver isso. (BULAWAYO, 2014, p.138)

Pouco depois de sua chegada aos Estados Unidos, a tia Fostalina muda de cidade e passa a viver em Washington. $\mathrm{Na}$ escola local, Darling passa pela experiência do bullying:

Quando cheguei a Washington, queria morrer. As outras crianças implicavam comigo por causa do meu nome, do meu sotaque, do meu cabelo, do jeito que eu conversava ou dizia coisas, do jeito que eu me vestia, do jeito que eu ria. Quando implicam 
com você por causa de alguma coisa, primeiro você tenta consertar essa coisa para que as implicâncias parem, mas aquelas crianças malucas implicavam comigo por tudo, até mesmo as coisas que eu não tinha como mudar, e isso continuou acontecendo e continuou acontecendo até que no fim simplesmente tudo parecia errado dentro da minha pele, do meu corpo, das minhas roupas, da minha língua, da minha cabeça. (BULAWAYO, 2014, p.149)

O peso da diferença e da discriminação faz com que Darling deseje ser uma pessoa diferente, ainda que, para isso, tenha de apagar os traços de sua própria identidade. Não era a primeira vez que Darling desejara ser outra pessoa. Quando ainda vivia no Paraíso, fotógrafos da CNN e da BBC haviam tirado fotos dela. Fotos que, provavelmente, foram utilizadas em reportagens ou publicadas em jornais, mas em nenhum momento perguntaram o seu nome. Para eles, ela era absolutamente invisível.

Viver em um país estrangeiro requer a adaptação à cultura local e esse passa a ser um dos objetivos de Darling, que jamais cogita sobre a possibilidade de voltar a viver na África. A América real, com todo o desencanto que lhe trouxera, exigia esforço para dominar bem o idioma, para adquirir novos hábitos, para forjar uma nova identidade. No capítulo intitulado "Como eles viviam", há uma síntese do que significa ser imigrante nos EUA: 
Como a América nos surpreendeu de início! Se você não estava feliz com o seu corpo, podia ir a um médico e dizer, por exemplo, Doutor, nasci no corpo errado, por favor, me conserte [...] Observamos as pessoas enviando seus pais para longe, para serem cuidados por estranhos [...] Observamos coisas estranhas como essas, coisas que nunca tínhamos visto em nossa vida, e dissemos: Que tipo de país é este? [...] Como não estávamos em nosso país, não podíamos falar em nosso idioma [...] como não estávamos usando nosso idioma, dizíamos coisas que não queríamos dizer; o que realmente queríamos dizer, ficava dobrado dentro de nós [...] pelos vistos e passaportes, imploramos, nos desesperamos, mentimos, nos humilhamos[...] e quando chegamos à América, pegamos os nossos sonhos [...] e os pusemos de lado, não os perseguiríamos [...] não havia escola para nós [...] em vez de estudar, trabalhamos [...] abaixávamos a cabeça porque não éramos mais pessoas, éramos imigrantes ilegais. (BULAWAYO, 2014, p.211-213 - grifo nosso)

Muito embora, a realidade para Darling seja menos cruel, uma vez que pode contar com o suporte de Fostalina, seus conflitos não são menores. Quando deixou sua terra, Darling acreditava que logo voltaria para ver a mãe e os amigos. Mais tarde, estranhou as evasivas da tia quando tocava no assunto. Só muito tempo depois ela descobriu que, por ser imigrante ilegal, se saísse dos Estados Unidos não poderia mais voltar. E, como tantos outros, cujos pais morreram 
esperando a volta dos filhos, Darling começa a se acostumar à ideia de que o retorno é impossível. A exemplo do que Edward Said afirma em Reflexões sobre o exílio (2003), para ela, a partida significara uma fratura incurável com o seu país natal.

Os laços vão se dissolvendo aos poucos. Assim que chegou aos Estados Unidos, Darling escrevia à família, embora buscando deixar de fora os aspectos negativos do país que a acolhera:

Tomava cuidado para deixar certas coisas de fora também, por exemplo, o clima que era horrível [...] a casa onde a gente morava não era nem um pouco parecida com as que a gente tinha visto na tevê quando éramos pequenos, [...] ela não era feita de tijolos, mas de tábuas [...] quando chovia essas tábuas mofavam e cheiravam mal [...] nas noites de verão tinha às vezes o pá-pá-pá de tiros na vizinhança [...] tinha gente pobre que morava na rua, segurando cartazes para pedir dinheiro. Eu deixava essas coisas de fora [...] porque elas me envergonhavam, porque faziam com que a América não se parecesse com a Minha América, aquela com a qual eu sempre tinha sonhado no Paraíso. (BULAWAYO, 2014, p.167)

Com o tempo, a frustração decorrente da falta de correspondência entre a América dos seus sonhos e a América real fez com que as cartas fossem rareando até cessarem por completo. As cartas são substituídas por esparsas conversas por meio do Skype. Por mais que tente se convencer 
de que o distanciamento é fruto da impossibilidade de retorno, na realidade, a permanência nos Estados Unidos é uma opção sua. Resta-lhe, assim, construir novas raízes em solo americano. O processo de reterritorialização nada mais é do que essa reconstrução do sentido de pertencimento e o surgimento de uma nova identidade, híbrida, porque decorrente do encontro entre culturas.

Em "No seu pescoço", a protagonista, Akunna, é uma nigeriana que emigra para os Estados Unidos após ser sorteada na loteria do Green Card, cuja candidatura havia sido feita por um tio que lá vivia, e parte para os Estados Unidos repleta de esperanças construídas a partir do imaginário de seu povo sobre o American way of life. A alegria decorrente dessa oportunidade é compartilhada com parentes e amigos e que assomam à sua casa pouco antes da partida, com muitos pedidos e recomendações. A falta de qualidade de vida da jovem é atestada pela descrição que o narrador faz da casa: pequena, com paredes descascadas e sem condições de acomodação para os visitantes.

Logo depois de você ganhar a loteria do visto americano, eles lhe disseram: daqui a um mês, você vai ter um carro grande. Logo, uma casa grande [...] Batalhões deles entraram no quarto em Lagos que você dividia com seus pais e três irmãos, apoiando-se nas paredes sem pintura porque não havia cadeiras para todos, para se despedir em voz alta e lhe 
dizer, em voz baixa, o que queriam que você Ihes enviasse. (ADICHIE, 2009, p.106)

Entretanto, semelhantemente ao que ocorre com Darling, a recepção nos EUA, não ocorre do modo que esperava. Akunna é hospedada por um tio que morava numa pequena cidade "de gente branca" no Maine. Ele Ihe contara que tinha um salário acima da média porque a empresa para a qual trabalhava necessitava comprovar diversidade nas contratações, o que compensava o deslocamento da sua esposa, por cerca de uma hora, em busca de uma cabeleireira apta a tratar de cabelos crespos. Há, indubitavelmente, um teor sociocrítico nessa revelação do tio à sobrinha, pois demarca com clareza os espaços sociais de brancos e negros. $\mathrm{Na}$ faculdade comunitária que a jovem passa a frequentar, o seu cabelo trançado passa a ser foco das conversas, fazendo com que se sinta como um animal em um zoológico:

Elas perguntaram onde você tinha aprendido a falar inglês, se havia casas de verdade na África e se você já tinha visto um carro antes de vir para os Estados Unidos. Olharam boquiabertas para o seu cabelo. Ele fica em pé ou cai quando você solta as tranças? Elas queriam saber. Fica todo em pé? Como? Por quê? Você usa pente? Você sorria de um jeito forçado enquanto elas faziam essas perguntas. Seu tio the disse que aquilo era esperado; uma mistura de ignorância e arrogância foi como ele definiu. (ADICHIE, 2009, p.107) 
A princípio, a estada na casa do tio lhe dá segurança e mantém o elo com a terra natal, pois falam o mesmo idioma igbo e tem os mesmos hábitos alimentares, porém, a aparente amabilidade do tio - que mais tarde o leitor descobre não ter laços de consanguinidade com a jovem, uma vez que é irmão de uma cunhada do pai de Akunna esconde segundas intenções, que são reveladas quando este a assedia sexualmente:

Até que seu tio entrou no porão apertado onde você dormia ao lado de caixas e embalagens velhas e puxou-a com força para perto dele, apertando sua bunda, soltando gemidos. Ele não era seu tio de verdade; na verdade, ele era irmão do marido da irmã de seu pai, não parente de sangue. Depois que você o empurrou para longe, ele se sentou na sua cama - a casa era dele, afinal de contas -, sorriu e disse que você não era mais criança, já tinha vinte e dois anos. Se você deixasse, ele faria muitas coisas por você. As mulheres espertas faziam isso o tempo todo. Como você achava que aquelas mulheres com bons salários em Lagos conseguiam aqueles empregos? $\mathrm{E}$ até as mulheres em Nova York? (ADICHIE, 2009, p.107)

Sob a pretensa desculpa de que era assim que as coisas funcionavam na América e de que "as mulheres espertas faziam isso o tempo todo", ele tenta coagi-la a aceitar suas investidas. A jovem decide, então, partir e o faz mesmo sem condições de sobreviver sozinha e sem apoio. Na manhã 
seguinte, a jovem pega um ônibus e vai para Connecticut, a última parada, onde começa a trabalhar como garçonete.

Sem ter condições financeiras para continuar seus estudos, passa a ler na biblioteca pública a bibliografia dos cursos que desejaria frequentar. Sua existência é alimentada pelas lembranças dos familiares e da Nigéria:

Às vezes, ficava sentada no colchão cheio de bolotas de sua bicama e pensava no seu país - nas suas tias que vendiam peixe seco e banana-da-terra na rua, adulando os passantes para que comprassem com elas e logo gritando insultos para aqueles que recusavam; nos seus tios, que bebiam o gim nacional e espremiam suas famílias e suas vidas em apenas um cômodo; nos amigos que tinham vindo se despedir de você, se regozijando porque você havia ganhado a loteria do visto americano, confessando a inveja que sentiam; nos seus pais, que muitas vezes davam as mãos quando caminhavam para a igreja no domingo de manhã, fazendo com que os vizinhos rissem e brincassem com eles; em sua mãe, cujo salário mal dava para pagar os estudos dos seus irmãos na escola de ensino médio onde os professores davam nota dez para quem lhes passava um envelope de papel pardo. (ADICHIE, 2009, p.108)

A exemplo de tantos imigrantes que saem de seus países para tentar a sorte no exterior, a protagonista envia metade de seus ganhos mensais para os pais, endereçando o envelope à estatal onde sua mãe trabalha como faxineira. 
Não escreve nada, por achar que não há o que dizer, nem tampouco coloca seu endereço no remetente. A utopia que Ihe trouxera tanto júbilo na sua ida para os Estados Unidos se desfizera. A América não era o Eldorado. Mais tarde, começa a sentir o desejo de narrar o estranhamento ante o modus vivendi dos estadunidenses, o choque cultural, mas, ainda assim, não o faz:

Quis escrever sobre a surpreendente franqueza das pessoas nos Estados Unidos, sobre como elas pareciam ansiosas para the falar da luta de sua mãe contra o câncer, sobre o bebê prematuro da cunhada, o tipo de coisa que a gente devia esconder ou revelar apenas para os parentes que nos queriam bem. Quis escrever sobre como as pessoas deixavam tanta comida nos pratos e largavam algumas notas de um dólar amassadas sobre a mesa, como se fosse uma oferenda, uma expiação pela comida desperdiçada. Quis escrever sobre a criança que começou a chorar, puxar os cabelos louros e empurrar os cardápios da mesa e, em vez de os pais a obrigarem a calar a boca, imploraram para que ficasse quieta, uma criança de no máximo cinco anos de idade, até que acabaram levantando e indo embora. Quis escrever sobre as pessoas ricas que usavam roupas esfarrapadas e tênis puídos, que pareciam os vigias noturnos das grandes propriedades de Lagos. Quis escrever que os americanos ricos eram magros e os pobres, gordos, e que muitos não tinham uma casa e um carro grandes. (ADICHIE, 2009, p.109) 
Do mesmo modo que a protagonista de Precisamos de novos nomes, Akunna sente o peso da invisibilidade social e da solidão, que a levam a esmurrar as paredes até ficar com manchas roxas nos braços. A falta de conhecimento dos norte-americanos sobre a África a destitui, inclusive, de sua identidade cultural, pois frequentemente é identificada como jamaicana: "achavam que qualquer negro com sotaque estrangeiro era jamaicano. Alguns que adivinhavam que você era africana diziam que adoravam elefantes e queriam fazer um safári" (ADICHIE, 2009, p.110).

O envolvimento de Akunna com um jovem branco que frequenta o restaurante em que trabalha como garçonete ameniza a saudade de casa. A sensação de aperto no pescoço que metaforiza a dificuldade de adaptação desaparece e marca o princípio de uma efetiva reterritorialização. 0 interesse e conhecimento que ele demonstra ter pela África a cativam, mas não diminuem o impacto da reação das pessoas ao vê-los juntos:

Pela reação das pessoas, você sabia que vocês dois eram anormais - o jeito como os grosseiros eram grosseiros demais e os simpáticos, simpáticos demais. As velhas e os velhos brancos que murmuravam e o encaravam, os homens negros que balançavam a cabeça para você, as mulheres negras com pena nos olhos, lamentando sua falta de autoestima, seu desprezo por si 
mesma. Ou as mulheres negras que davam sorrisos rápidos de solidariedade; os homens negros que se esforçavam demais para perdoar você, dizendo oi para ele de maneira excessivamente óbvia. (ADICHIE, 2009, p.115-116)

A essa altura, Akunna percebe que, ainda que se integre à sociedade estadunidense e obtenha definitivamente a cidadania americana ${ }^{4}$, na condição de membro de uma minoria étnica, estará sempre à margem. A percepção desse estado de coisas aliada a diferenças de postura em relação a determinados valores, como, por exemplo, a importância de uma formação superior - que ela valoriza e ele não leva a sério - , fazem com que ela volte a se sentir só e decida, finalmente, escrever a casa, dando o seu endereço. A resposta traz o comunicado do falecimento do pai:

Seu pai estava morto; simplesmente caiu sobre o volante do carro da empresa. Há cinco meses, escreveu ela. Eles tinham usado parte do dinheiro que ela enviara para dar a ele um bom funeral: mataram um bode para os convidados do velório e compraram um bom caixão. Você se enroscou na cama, apertou os joelhos contra o peito e tentou lembrar o que estava fazendo quando seu pai morreu, o que tinha feito durante todos aqueles meses em que ele já estava morto. Talvez seu pai tivesse morrido no dia em que

4 O Green Card é o documento de residente permanente legal, que permite que o estrangeiro tenha autorização de trabalho e permanência no país. A residência permanente não tem prazo de validade, mas o documento sim e precisa ser renovado a cada dez anos. A única maneira de um estrangeiro obter a cidadania americana é por meio da naturalização. 
você sentiu calafrios pelo corpo todo, ficando com os pelos duros como grãos de arroz crus, sem saber explicar por quê, no dia em que Juan brincou que você devia ficar no lugar do cozinheiro, para poder se esquentar com o calor da cozinha. Talvez seu pai houvesse morrido num dos dias em que você dirigiu até a cidade de Mystic, ou assistiu a uma peça em Manchester, ou jantou no Chang's. (ADICHIE, 2009, p.117)

Ao decidir voltar à Nigéria, ela sabe que esse retorno será também um reencontro com as memórias e a tradição, com tudo o que abandonara e preferira ignorar durante todo o tempo em que estivera nos Estados Unidos. Essa certeza faz com que recuse a oferta do namorado para acompanhála. Mais do que a culpa por deliberadamente ter deixado de manter contato com o pai, que jamais retornaria a ver, afeta-lhe a sensação de estar de fato fora de lugar. Parte prometendo retornar, mas, intimamente, sabe que é uma promessa vazia.

\section{CONSIDERAÇÕES FINAIS}

As obras examinadas contêm representações da difícil relação do imigrante com o território que abandona, ou seja, com o seu lugar antropológico, e da complexa relação com o país de acolhimento, onde, na maioria das vezes, se sente deslocado e marginalizado. 
As duas protagonistas passam por um processo de reterritorialização, por meio do qual tentam recuperar o sentido do pertencimento. Entretanto, ao se integrarem à sociedade estadunidense, as relações com a terra natal são obliteradas pelas experiências cotidianas. Para Darling, a reterritorialização culmina na decisão de permanecer nos Estados Unidos; para Akunna, o retorno é inevitável, pois sente que a integração à nova pátria não ocorre de modo efetivo. Há dentro dela uma lacuna da qual só se apercebe com a morte do pai.

Os pontos de convergência entre as duas obras demonstram que a temática dos deslocamentos continua presente na literatura contemporânea, porém não como mera descrição do processo de aculturação, mas com um insight nas questões afetivas que, afinal, são responsáveis pelos laços que estabelecemos com nosso lugar de origem.

\section{REFERÊNCIAS}

ADICHIE, Chimamanda Ngozi (2009). No Seu Pescoço. Julia Romeu (Trad.). São Paulo: Companhia das Letras.

ANDERSON, Benedict (2007). Comunidades Imaginadas. São Paulo: Companhia das Letras.

AUGÉ, Marc (1994). Não-lugares: introdução a uma antropologia da sobremodernidade. Lúcia Mucznik (Trad.). Lisboa: Bertrand Editora.

BHABHA, Homi (2011). "O Entrelugar das Culturas". In: COUTINHO, Eduardo (Org.). O bazar global e o clube dos cavalheiros ingleses. Rio de Janeiro: Rocco. p.80-94. 
BLUME, Rosvitha Friesen (2014). "Traços migratórios e tradução cultural na obra ensaística de Herta Müller e de Yoko" Tawada. Itinerários, Araraquara, SP, (38), 59-72, jan./jun.

BULAWAYO, NoViolet (2014). Precisamos de novos nomes. Adriana Lisboa (Trad.). São Paulo: Biblioteca Azul.

CANCLINI, Néstor Garcia (2008). Diferentes, desiguais e desconectados. Rio de Janeiro: Editora da URFJ.

CARREIRA, Shirley de Souza Gomes et al. (2015). Travessias: estudos de literatura e imigração. UNIABEU, Belford Roxo.

(2009). "O escritor migrante e a ficção diaspórica". Cadernos de Pesquisa Interdisciplinar em Ciências Humanas, 10(96), 44-59.

(2012). "A representação da identidade em Hell-Heaven, de JhumpaLahiri". Soletras, Rio de Janeiro, RJ, (23). In https://www.epublicacoes.uerj.br/index.php/soletras/article/view/3806/2639 Acesso em 27.Nov.2018.

DELEUZE, Gilles; GUATTARI, Felix (1980). Mille plateaux: Capitalisme et schizophrénie 2. Paris: Minuit.

HALL, Stuart (1998). A identidade cultural na pós-modernidade. SP: DP\&A Editora.

RUSHDIE, Salman (1991). Imaginary Homelands. Essays and criticism 1981-1991. Londres: Granta Books.

SAID, Edward (2003). Reflexões sobre exílio e outros ensaios. Pedro Maia Soares (Trad.). São Paulo: Companhia das Letras.

Shirley de Souza Gomes Carreira é Doutora em Literatura Comparada (UFRJ), Mestre em Linguística Aplicada (UFRJ), com pesquisa de PósDoutorado em Literaturas de Língua Inglesa (UERJ). É Professora Adjunta da Faculdade de Formação de Professores da UERJ e docente permanente do Mestrado em Estudos Literários do Programa de Pós-Graduação em Letras e Linguística da UERJ. Publicações: Diásporas e deslocamentos: travessias críticas, Poéticas do Contemporâneo, Travessias: estudos de literatura e migração e Memória, identidade e cultura: ensaios. É líder 
do Grupo de Pesquisa "Poéticas da Diversidade". Página pessoal: https:// shirleysgcarreira.wordpress.com/ E-mail: shirleysgcarr@gmail.com.

Victória Cristina de Sousa Bezerra é Mestranda em Estudos Literários no Programa de Pós-Graduação em Letras e Linguística da UERJ e integrante do Grupo de Pesquisa "Poéticas da Diversidade”. E-mail: vicbezerra12@ gmail.com 